\title{
Compressive Strength of Woven and Strand of Recycled Polyethylene Terephthalate (PET) Reinforced Concrete
}

\author{
ANDREI MIHAI BACIU ${ }^{1}$, IMRE KISS ${ }^{2 *}$, ILARE BORDEASU ${ }^{3 *}$, \\ LAVINIA MADALINA MICU** \\ ${ }^{1}$ University Politehnica Timisoara, Faculty of Engineering Hunedoara, Center for Research in Advanced Materials \& \\ Technologies, 5 Revolutiei, 331128, Hunedoara, Romania \\ ${ }^{2}$ University Politehnica Timisoara, Faculty of Engineering Hunedoara, Department of Engineering \& Management, \\ 5 Revolutiei, 331128, Hunedoara, Romania \\ ${ }^{3}$ University Politehnica Timisoara, Faculty of Mechanical Engineering, 1 Mihai Viteazu Blvd., 300222, Timisoara, \\ Romania \\ ${ }^{4}$ University of Agricultural Sciences and Veterinary Medicine of Banat King Mihai I from Romania, 119 Calea Aradului, \\ 300645, Timisoara, Romania
}

\begin{abstract}
Woven fiber reinforced concrete is a material, which contains various quantities of polymer materials in composition, in addition to the conventional components of an ordinary concrete (mineral binder-cement, aggregates, water and additives). The present work refers to the concrete in which the reinforcement is made of polymeric materials (polyethylene terephthalate), originated from the recycling programs of PET-type packaging. The experimental program was aimed at constructing some samples of woven fiber reinforced concrete from recycled material coming from PET packaging wastes, their testing to the compression demands and the comparison of results with the characteristics of the standardized samples of concrete (class C30/37). Based on a sufficient number of determinations, certain correlations can be established between the compressive strength of the concrete at 28 days depending on the dosage of components (aggregate, binder, and reinforcement), water / cement ratio, reinforcement volume, etc., essential parameters from a compositional point of view. These correlations, customized by cement type and strength class, are very important to determine - with approximation - to what dosage of components (aggregate, binder, reinforcement) the respective level of compressive strength of concrete is obtained.
\end{abstract}

Keywords: polyethylene terephthalate PET-type packaging wastes, woven fiber reinforced concrete, PET fiber woven, PET fiber rope strand, compressive strength

\section{Introduction}

The development of the construction sector imposes the finding of some solutions of using cheaper materials, locally, considering the magnitude of the sector, it requires the consumption of natural aggregates, binders, armatures, etc., which are difficult to ensure from traditional sources [1-9]. It must equally be ensured that the exigencies (safety, durability) must be met throughout the entire life span of the construction [1,2,10-12].

Concrete is one of the most widely-used materials in the construction industry, due to the continuous adaptability as well as the high performance obtained throughout the years. In reinforcing concrete, fibers are increasingly used because they provide control of the cracking process and increase the resistance to impact, shocks and temperature variations [1,2,10-18]. Fibers can be used in the preparation of concrete for different building elements, including rigid concrete structure, pedestrian and concrete pavements and borders, support walls or bulwark foundations, but they are starting to be used more and more in the production of prefabricated [1-12].

*email: imre.kiss@upt.ro,ilarica59@gmail.com,lavimicu@yahoo.com 
The fibred reinforced concrete (Figure 1) is more flexible, having a higher resistance to cracking caused by its contractions in the plastic state, being by far lighter and safer to use than the traditional [2,10-12]. Unlike conventional or metallic fiber reinforcement, the use of polymeric fibers improves the strength of the concrete without the risk of corrosion of the reinforcement, while maintaining the durability [5-8].

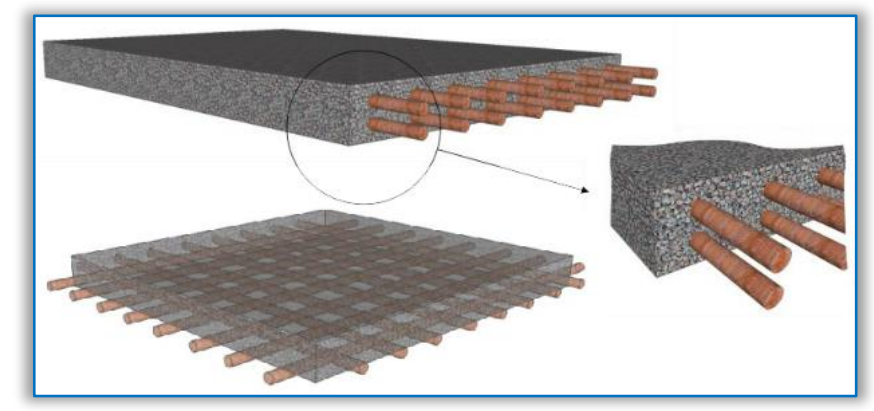

Figure 1. Fibre-reinforced concrete

\section{Materials and methods}

Non-reinforced concrete (class C30/37) and reinforced concrete with reinforcements from recycled polyethylene terephthalate (PET) waste were made in laboratory conditions, on an exact recipe and in accordance with the requirements.

The present work refers to the concrete in which the reinforcement is made of polymeric materials (polyethylene terephthalate packaging wastes). In this sense, the influence of two woven and braided polyethylene terephthalate (PET) reinforcements on the compression characteristics of the concrete was studied. In the first of the concrete reinforcement methods, the extraction of yarns from polyethylene terephthalate (PET) packaging was chosen (Figure 2), using a handmade bottle cutter, followed by a mesh-shaped braiding process (Figure 3.a). The second concrete reinforcement method uses reinforcements in the form of polymer rope, obtained from weaving the polyethylene terephthalate (PET) long yarns (Figure 3.b). Both methods are described below.
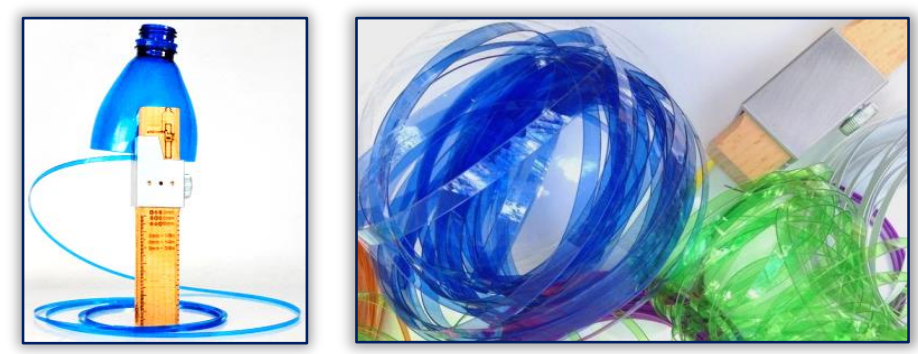

Figure 2. Extraction of long flat strips (yarns) from polyethylene terephthalate (PET)

(a)
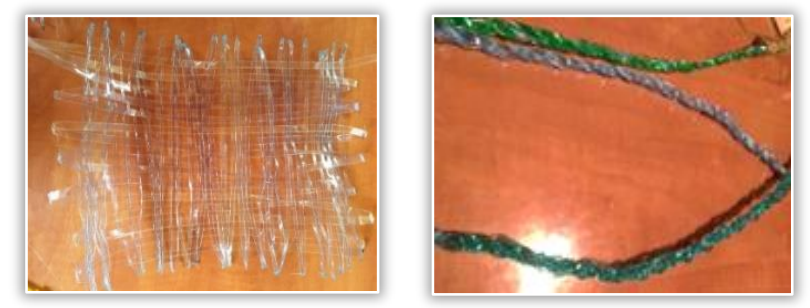

(b)

Figure 3. Preparing the PET reinforcement: a) PET mesh-shaped woven; b) PET rope strand 
Compressive strength is one of the main criteria for assessing the quality of a concrete. $[1,4,8,12]$ The knowledge of the compressive strength gives sufficiently precise indications on the resistance to other demands as well as on the other physical-mechanical properties of the concrete.[1,4,12] The determination of the compressive strength of the reinforced concrete (at 28 days) is determined according to $[12,19]$ and $[12,20]$, based on the test carried out on a minimum number of three samples of cubic form (cubic strength).

It is possible to obtain an appreciable resistance to corrosion through a carefully made, well compacted concrete. The determination of the volumetric mass (density) is made according to [12,21]. It is expected that the determined value of the concrete density of class C8/10-C35/45 will be in the range $2200-2400 \mathrm{~kg} / \mathrm{m}^{3}$ [12].

\section{Experiments}

\section{Making of reinforcements}

Firstly, the yarns made from polyethylene terephthalate (PET) bottles were extracted (Figure 4). After extraction of 3-5 mm yarn and braiding it on the special woven support, the PET mesh-shaped woven will be prepared for use in the experiment no.2.

The braiding process has been made using a metal support drilled on the edges, made specifically for this process from metal profiles connected as a rectangle and drilled on the edges (Figure 5). Polyethylene terephthalate threads are inserted into these holes throughout the length and the entire width, making the manual braiding. The braiding stand being larger than the formworks of test specimens, results in a net larger than approximately $25 \mathrm{~cm}$ wide per $40 \mathrm{~cm}$ width. The resulting PET mesh-shaped woven require cutting to the size of the joint of the test specimens $(15 \times 15 \times 15 \mathrm{~cm})$. After cutting the PET mesh-shaped woven to the required dimensions, a weight of the 10 grams woven net is obtained, approximately $0.6 \%$ relative to the cement quantity of the grade C30/37 concrete used as matrix.
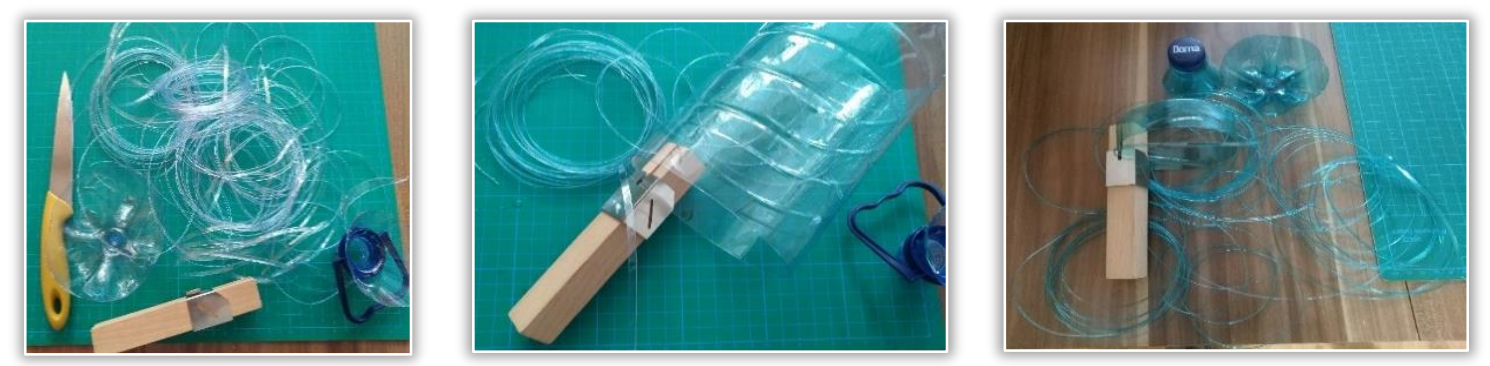

Figure 4. Extraction in yarns and obtaining the long polyethylene terephthalate (PET) yarn

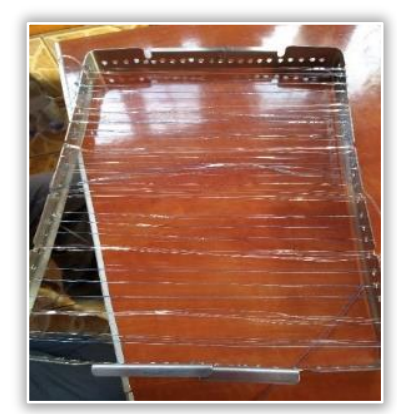

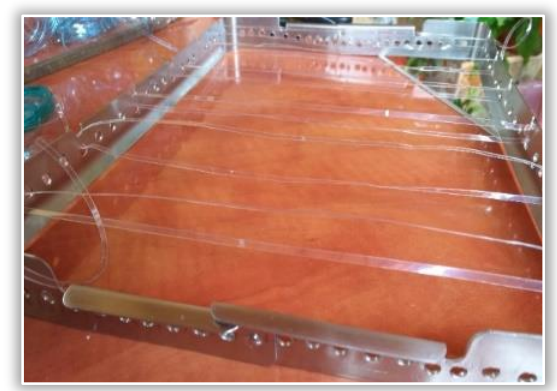

Figure 5. The braiding process

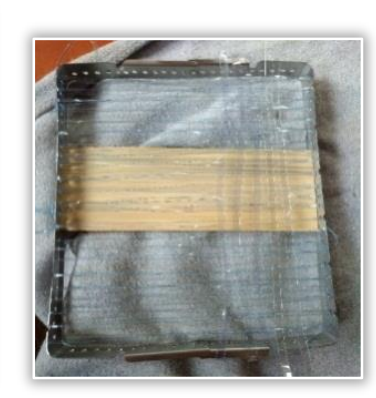



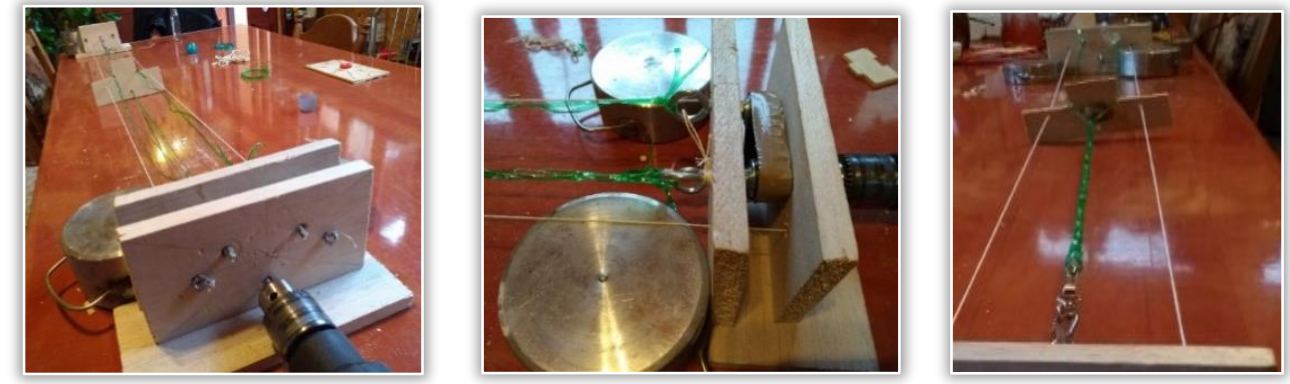

Figure 6. Apparatus for weaving in rope

Using the long polyethylene terephthalate (PET) yarns, they are inserted into a special made-up apparatus (Figure 6) for weaving them in special ropes which will be used as reinforcement in the reinforced concrete samples (experiment no. 3). Thus, 18 polyethylene terephthalate (PET) yarns (6 through each clamping element and all 18 attached to the opposite end) passed. The thickness is about $1 \mathrm{~cm}$ (Figure 7.a). After making the ropes it was necessary to cut them to the dimensions necessary to get into the laboratory formworks $(15 \times 15 \times 15 \mathrm{~cm})$. The long ropes have been cut about $14-15 \mathrm{~cm}$ and then bonded (Figure 7.b).

a)

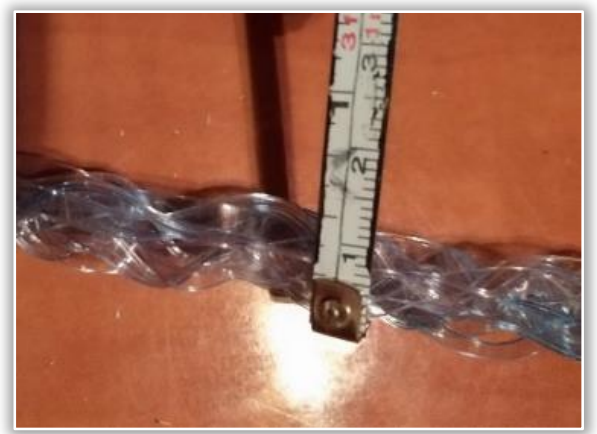

Figure 7. The polyethylene terephthalate (PET) rope and the rope strands used as reinforcement (b)

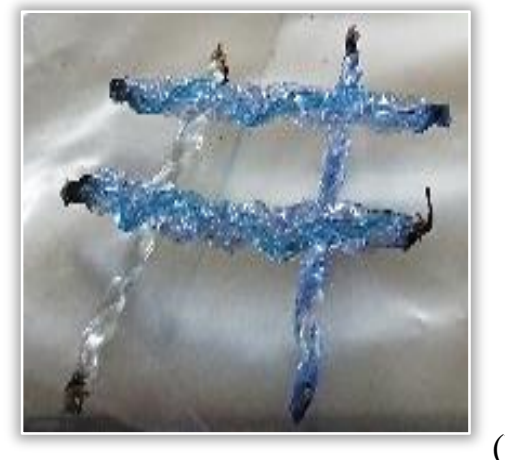



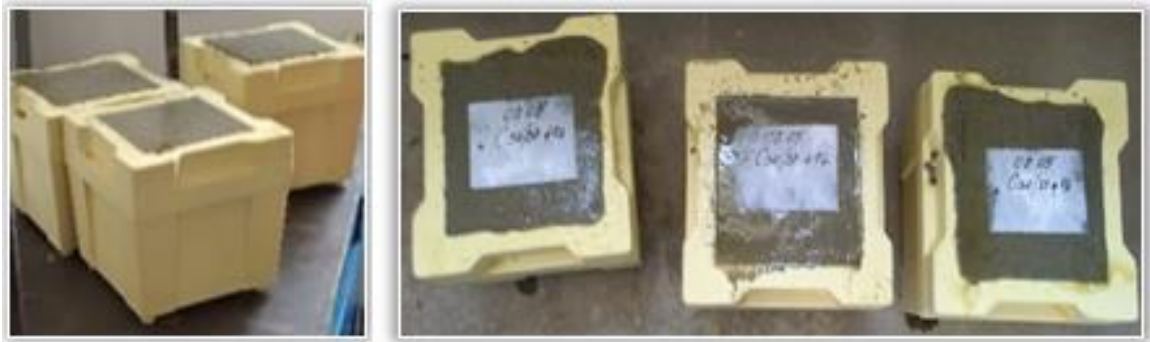

Figure 8. Preparing and labelling the concrete samples
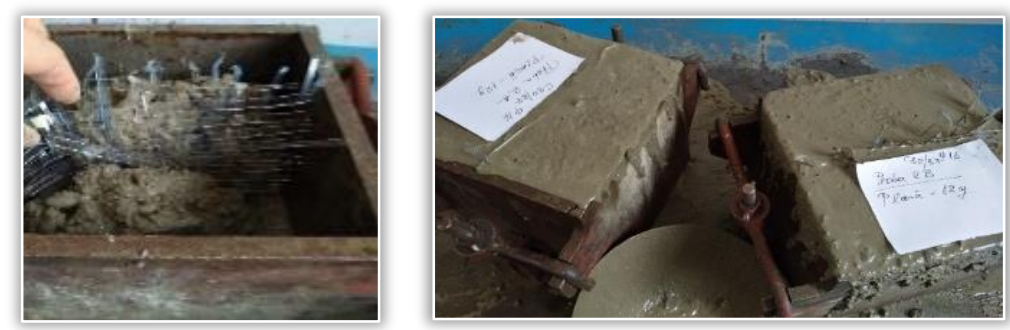

Figure 9. The reinforcing process with PET mesh-shaped woven and labelling the samples

The next day, the specimens were stripped and then kept in optimal conditions in the specialized laboratory for 28 days for maturation.[12]

\section{Making the samples reinforced with PET rope strands}

Special formworks were prepared for the samples from experiment no. 3 (Figure 10). After proper casting and vibration of the samples, they were labelled (Figure 11) accordingly to be easily and correctly identified at the time of the laboratory tests. The next day the specimens were stripped and then kept in optimum conditions in the specialized laboratory for 28 days for the proper maturation of the concrete, necessary for carrying out the laboratory tests [12].
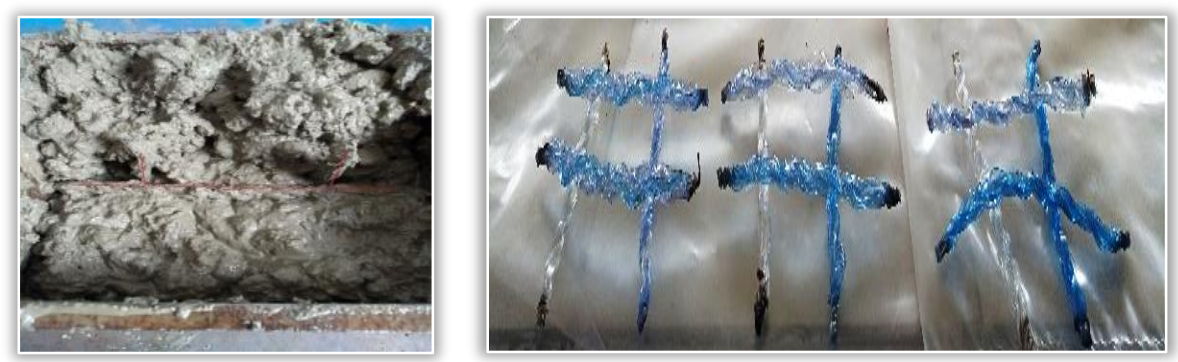

Figure 10. The PET flakes reinforcing process with PET rope strands

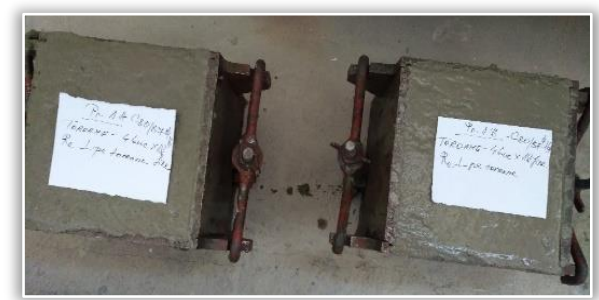

Figure 11. Labelling the reinforced concrete samples of experiment no.3 


\section{Results and discussions}

After the 28 days necessary to achieve the maturation of all the specimens it is possible to proceed to the accomplishment of the laboratory loads. The UTest-Autocon testing equipment was used to determine the compression load (Figure 12 and Figure 13). All the experimental values on the compression strength test are presented in Table 1.

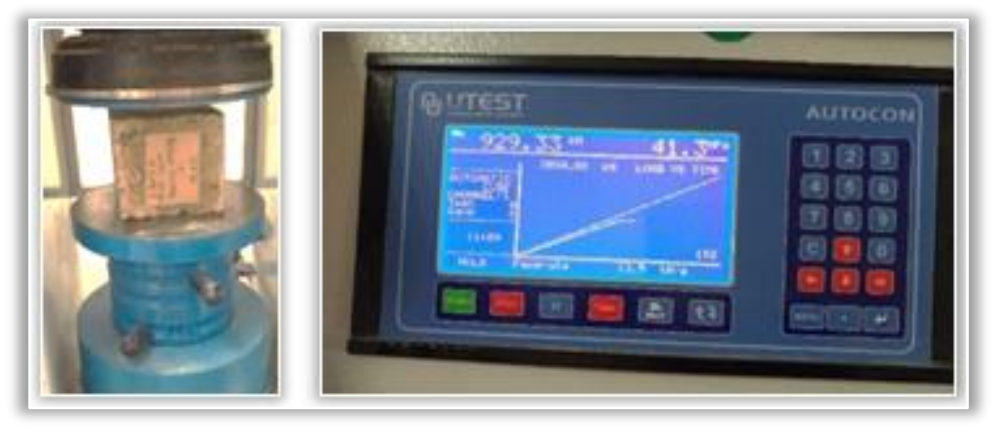

Figure 12. Compression strength test of with PET mesh-shaped woven' reinforced concrete samples

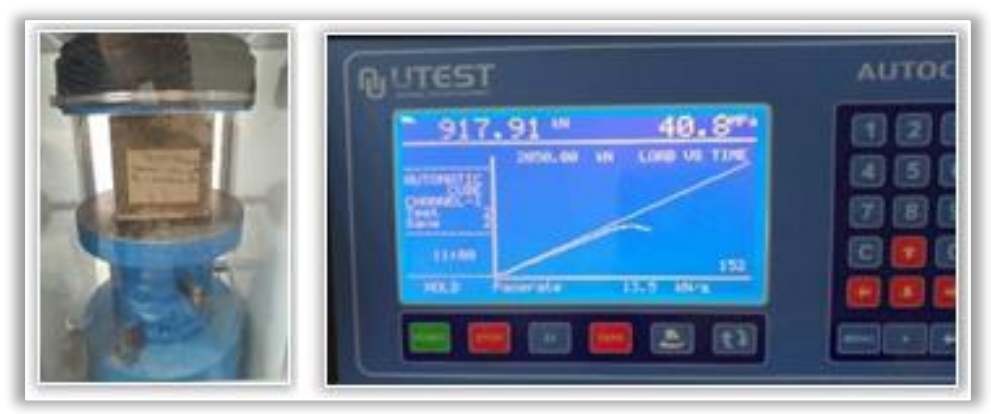

Figure 13. Compression strength test of with PET rope strands' reinforced concrete samples

Table 1. Experimental values

\begin{tabular}{|c|c|c|c|c|c|}
\hline \multirow{2}{*}{ No. experiment } & Characteristics & \multicolumn{3}{|c|}{ Experimental values } \\
\cline { 2 - 5 } & $\mathbf{1}$ & $\mathbf{2}$ & $\mathbf{3}$ & Average value \\
\hline \multirow{2}{*}{$\begin{array}{c}\text { Experiment no.1: } \\
\text { Concrete samples } \\
\text { (etalon) }\end{array}$} & Breaking force, $[\mathrm{kN}]$ & 906 & 908 & 886 & 900 \\
\cline { 2 - 6 } & Compression strength, $[\mathrm{N} / \mathrm{mm} 2]$ & 40.3 & 40.4 & 39.4 & 40.0 \\
\cline { 2 - 6 } & Mass of the samples, $[\mathrm{kg}]$ & 7.90 & 7.98 & 8.01 & 7.96 \\
\hline $\begin{array}{c}\text { Experiment no.2: } \\
\text { PET mesh-shaped } \\
\text { woven' reinforced } \\
\text { concrete samples }\end{array}$ & Density of concrete, $[\mathrm{kg} / \mathrm{m} 3]$ & 2341 & 2364 & 2373 & 2360 \\
\cline { 2 - 6 } & Breaking force, $[\mathrm{kN}]$ & 935 & 934 & 929 & 933 \\
\hline $\begin{array}{c}\text { Experiment no.3: } \\
\text { PET rope strands' } \\
\text { reinforced concrete } \\
\text { samples }\end{array}$ & Compression strength, $[\mathrm{N} / \mathrm{mm} 2]$ & 41.6 & 41.5 & 41.3 & 41.45 \\
\cline { 2 - 6 } & Mass of the samples, $[\mathrm{kg}]$ & 8.10 & 8.22 & 8.22 & 8.18 \\
\cline { 2 - 6 } & Density of concrete, $[\mathrm{kg} / \mathrm{m} 3]$ & 2400 & 2436 & 2436 & 2424 \\
\hline
\end{tabular}

We have the following comments and remarks:

- The dispersed reinforced concrete samples were weighed to determine the densities of each. The average determined value of the density of concrete from class C30/37 was within the recommended range (between 2200-2400 kg/m3), being $2360 \mathrm{~kg} / \mathrm{m} 3$ (in the concrete sample), 2424 $\mathrm{kg} / \mathrm{m} 3$ (in the test with PET mesh-shaped woven's reinforcement), respectively $2383 \mathrm{~kg} / \mathrm{m} 3$ (in the test with PET rope strands' reinforcement) - Figure 14. 
- concrete sample), $8.18 \mathrm{~kg}$ (in the test with PET mesh-shaped woven's reinforcement) respectively $8.04 \mathrm{~kg}$ (in the test with PET rope strands' reinforcement) - Figure 15.

- We started with the compression loading of the standard samples, with the average breaking force of $900 \mathrm{kN}$, resulting in an average resistance on the 3 samples of $40 \mathrm{~N} / \mathrm{mm} 2$ (Figure 15).

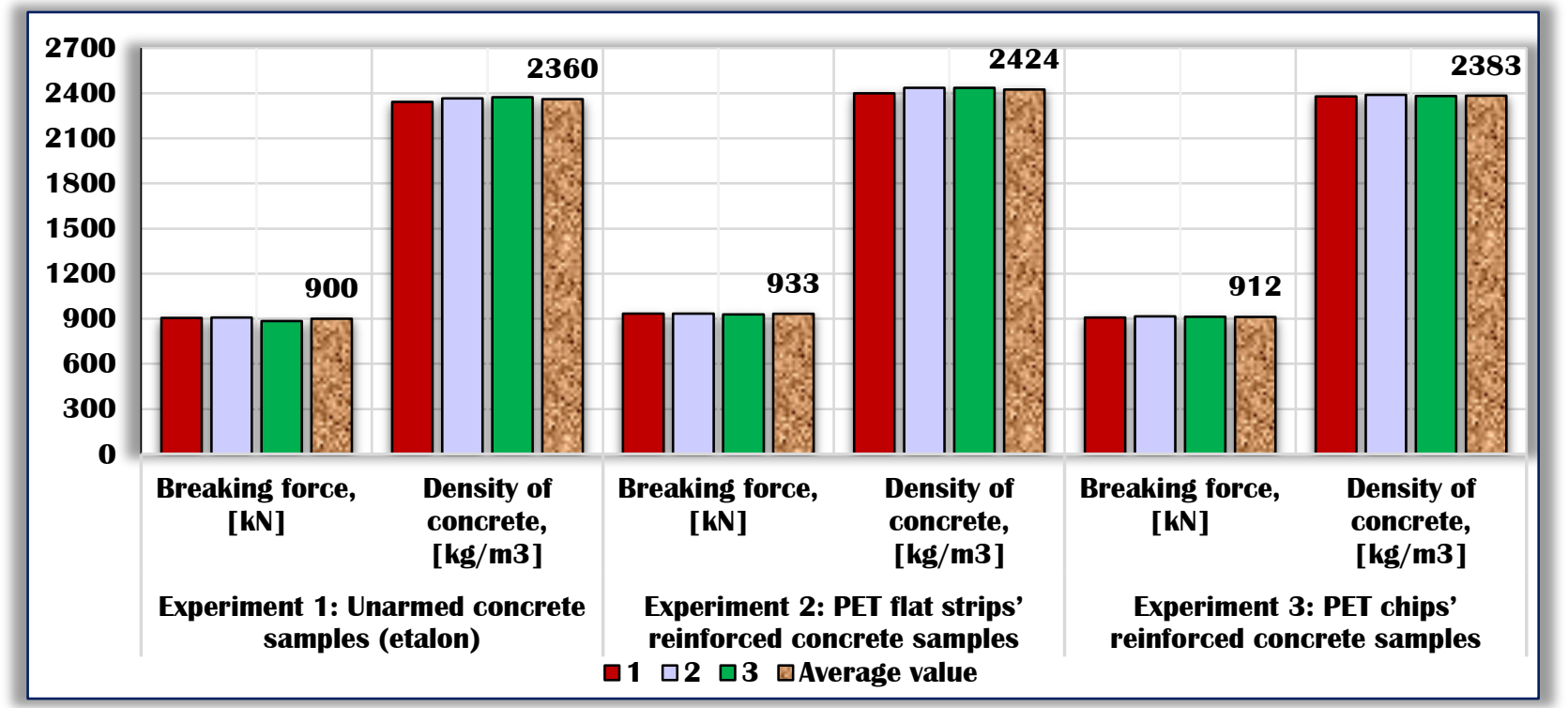

Figure 14. Breaking force and density of the concrete - Comparative study on the concrete samples, the PET mesh-shaped woven' reinforced concrete samples and the PET rope strands' reinforced concrete samples

- The mass of the samples (with the nominal area $22500 \mathrm{~mm}^{2}, 150 \times 150 \mathrm{~mm}$ ) was $7.96 \mathrm{~kg}$ (in the concrete sample), $8.18 \mathrm{~kg}$ (in the test with PET mesh-shaped woven's reinforcement) respectively $8.04 \mathrm{~kg}$ (in the test with PET rope strands' reinforcement) - Figure 15.

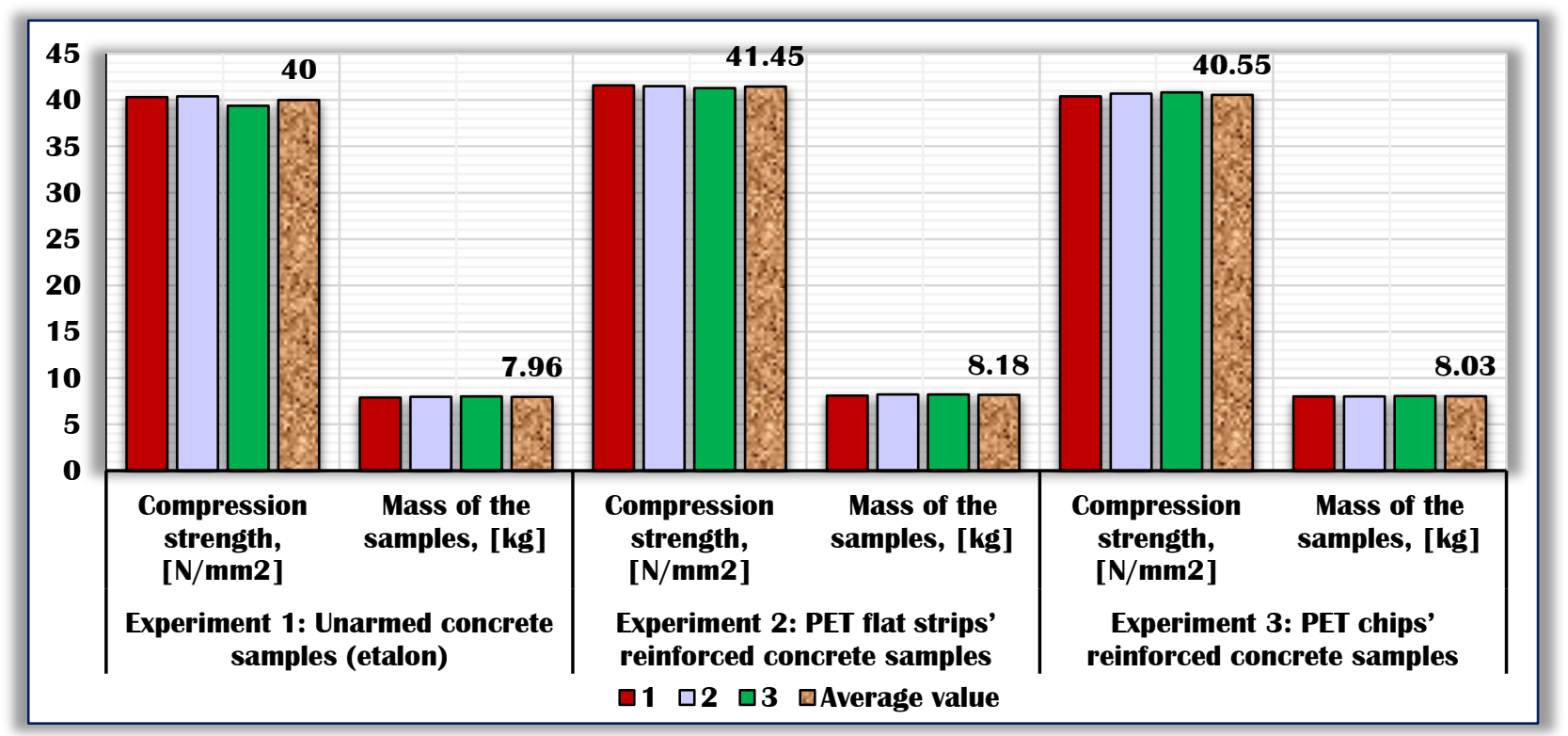

Figure 15. Compression strength and mass of the samples - Comparative study on the concrete samples, the PET mesh-shaped woven' reinforced concrete samples and the PET rope strands' reinforced concrete samples 
- We started with the compression loading of the standard samples, with the average breaking force of $900 \mathrm{kN}$, resulting in an average resistance on the 3 samples of $40 \mathrm{~N} / \mathrm{mm}^{2}$ (Figure 15).

- Compression loading of the concrete samples reinforced with polyethylene terephthalate (PET) mesh-shaped woven was performed with the average breaking force of $933 \mathrm{kN}$ (Figure 14). The results of the polyethylene terephthalate (PET) mesh-shaped woven reinforcement were satisfactory (Figure 15) because, with an average of the 3 tested samples, it showed an improvement of $1.45 \mathrm{~N} / \mathrm{mm}^{2}$, more precisely a total average resistance of $41.45 \mathrm{~N} / \mathrm{mm}^{2}$, an increase of $3.6 \%$ compared to the standard base samples of the matrix concrete class C30/37.

- Compression loading of the concrete samples reinforced with polyethylene terephthalate (PET) rope strands was performed with the average breaking force of $912 \mathrm{kN}$ (Figure 14). The average resistance obtained for the reinforcement with polyethylene terephthalate (PET) rope strands was $40.55 \mathrm{~N} / \mathrm{mm}^{2}$ (Figure 15), comparable to the case of polyethylene terephthalate (PET) meshshaped woven reinforcement and the case of standard concrete.

\section{Conclusions}

Fiber-reinforced composites with exceptionally high specific strengths and moduli have been produced that utilize low-density fiber and matrix materials. We studied the use of two types of reinforcement (woven mesh and rope strands made from recycled polyethylene terephthalate), analyzing the behavior of reinforced concrete with these polymer fibers, during the compression tests.

Having in view the presented results on the compression loading experiments on concrete reinforced with woven polymer fibers coming from recycled post-consumer polyethylene terephthalate (PET), we have the following conclusions:

-The reinforcement method using polyethylene terephthalate (PET) mesh-shaped woven is the most burdensome in terms of the process time because it takes a very long time to produce the braiding, so it can only be used industrially with the assistance of specialized machines for better performance.

-Although it requires the device to be made (apparatus for weaving in rope), the time of making the rope strands in relation to the mesh-shaped woven is relatively small (approximately 5 minutes for extraction in yarns and approximately 6 minutes for the rope strands). Also, the reinforcement times are relatively small;

-These polyethylene terephthalate (PET) reinforcement materials can take different shapes and sizes, such as woven (strands), in the form of plastic nets, but also three-dimensional. As in the case of PET mesh-shaped woven' reinforced concrete, the enhancements do not occur in the reinforcement of the rope strand's reinforced concrete, in the compression strength. We believe that such reinforcement coming from recycled polyethylene terephthalate wastes are much more feasible in the case of loads in the stretch test, where we expect the results to be considerable.

\section{References}

1.VISHNU, A., MOHANA, V., MANASI, S., PONMALAR, V., Use of polyethylene terephthalate in concrete - A brief review, International Journal of Civil Engineering and Technology, 8(8), 2017, pp. 279-282

2.SHAHIDAN, S., RANLE, N. A., MOHD ZUKI, S.S., SHEIKH KHALID, F., RIDZUAN, A.R.M.,. NAZRI, F.M., Concrete incorporated with optimum percentages of recycled polyethylene terephthalate (PET) bottle fiber, International Journal of Integrated Engineering, 10(1), 2018, pp. 1-8

3.SAIKIA, N., De BRITO, J., Waste polyethylene terephthalate as an aggregate in concrete, Materials Research, 16(2), 2013, pp. 341-350

4.SAIKIA, N., De BRITO, J., Mechanical properties and abrasion behaviour of concrete containing shredded PET bottle waste as a partial substitution of natural aggregate. Construction and building materials, 52, 2014, pp. 236-244 
5.GU, L., OZBAKKALOGLU, T., Use of recycled plastics in concrete: A critical review, Waste Management, 51, 2016, pp. 19-42

6.SHARMA, R., PAL BANSAL, P., Use of different forms of waste plastic in concrete - A review, Journal of Cleaner Production, 112(1), 2016, pp. 473-482

7.FADHIL, S., YASEEN, M., The production of economical precast concrete panels reinforced by waste plastic fibers, American Journal of Civil Engineering and Architecture, 2015, 3(3), pp. 80-85 8.KHALID, F.S., IRWAN, J.M., WAN IBRAHIM, M.H., OTHMAN, N., SHAHIDAN, S., Performance of plastic wastes in fiber-reinforced concrete beams, Construction and Building Materials, 183, 2018, pp. 451-464

9.WAROONKUN, T., PUANGPINYO, T., TONGTUAM, Y., The development of a concrete block containing PET plastic bottle flakes, Journal of Sustainable Development, 10(6), 2017, pp. 186-199

10.SHALABY, A., WARD, A., REFAEE, A., ABD-EL-MESSIEH, S., ABD-EL-NOUR, K., ELNASHAR, D., Compressive strength and electrical properties of cement paste utilizing waste polyethylene terephthalate bottles, Journal of Applied Sciences Research, 2013, 9(7), pp. 4160-4173

11.MARZOUK, O.Y., DHEILLY, R.M., QUENEUDEC, M., Valorization of post-consumer waste plastic in cementitious concrete composites, Waste Management, 27(2), 2007, pp. 310-318

12.KISS, I., BACIU, A.-M., BORDEAȘU, I., MICU, L.M., Compressive strength of stripes and flakes of recycled polyethylene terephthalate (PET) added concrete, Mater. Plast., emerging

13.TUDOSE, V., TUDOR, D. I., GHEORGHIU, H., GHIBAN, N., Comparative analysis of the mechanical behaviour of optical sighting devices made of plastic or metallic materials, Mater. Plast., 50(4), 2013, 319-322

14.TUDOR, D. I., PETRESCU, H., HADAR, A., ROȘU, A., Computer tomography investigation of defects in plastic material plates, Mater. Plast., 49(2), 2012, 123-128

15.BEJ, A., BORDEASU, I., MILOS, T., BADARAU, R., Considerations concerning the mechanical strength of wind turbine blades made of fiberglass reinforced polyester, Mater. Plast., 49(3), 2012, 212-218

16.MITELEA, I., VARZARU, N., BORDEASU, I., POPESCU, M., The high frequency welding aptitude of thermoplastic polymers, Mater. Plast., 46(1), 2009, 101-107

17.TUDOR, D. I., PARAUSANU, I., HADAR, A., Validation of models of plates with discontinuities made of plastic materials, through modal analysis, Mater. Plast., 49(3), 2012, 166-170

18.GOANTA, V., HADAR, A., LEITOIU, B., Experimental procedure designed to determine the elastic characteristics of fiber-reinforced polymeric composite materials, Mater. Plast., 47(4), 2010, 450-456

19.***SR EN 12390-1:2013, Test on reinforced concrete. Part 1: Shape, dimensions and other conditions for specimens and patterns

20.***SR EN 12390-3:2009, Test on reinforced concrete. Part 3: The compressive strength of the specimens

21.***SR EN 12390-7:2009, Test on reinforced concrete. Part 7: Reinforced concrete density

Manuscript received: 5.02.2020 